\title{
Can Tax Breaks Beat Geography? \\ Lessons from the French Enterprise Zone Experience
}

\author{
ONLINE APPENDIX
}

Anthony Briant* Miren Lafourcade $^{\dagger} \quad$ Benoît Schmutz $^{\ddagger}$

July 2014

\begin{abstract}
This online appendix complements the paper by Briant, Lafourcade, and Schmutz (forth.). In a first section, we provide additional details on the geography of the French enterprise zone program (ZFU): first, we develop two polar examples of ZFU and show that their topography is well approximated by the geographic indices we propose; then, we provide indirect evidence that the individual mobility patterns are indeed correlated with these geographic indices. In a second section, we provide additional regression results: first, we discuss the evolution of the impact of the program, through the measure of annual treatment effects; then, we provide evidence that our estimates of the average treatment effects are robust to the rule we apply to select the treatment and the control groups.
\end{abstract}

\footnotetext{
*Paris School of Economics (PSE); Anthony.Briant@m4x.org.

${ }^{\dagger}$ University Paris-Sud (RITM) and Paris School of Economics (PSE); miren.lafourcade@ens.fr; http:/ / www.parisschoolofeconomics.com/lafourcade-miren/. (Corresponding author)

${ }^{\ddagger}$ Howard University; benoit.schmutz@howard.edu; http:/ / sites.google.com/site/benoitschmutz/.
} 


\section{Details on the geography of ZFU}

\subsection{Two polar examples of ZFU}

We develop here two examples of ZFU: "Les 4000", located in a notorious northern suburb of Paris called "La Courneuve", and "Chantereigne-Montvilliers" located in the Northern part of Troyes, a city of about 60,000 inhabitants 100 miles east of Paris.

Table 1: The geographical features of "les 4000" and "Chantereigne-Montvilliers"

Panel A: Urban cut-offs between the neighborhood and the CBD

\begin{tabular}{|c|c|c|}
\hline & Les 4000 & Chantereigne \\
\hline Average river cut-offs to all CBDs in the MA & 56.127 & 0 \\
\hline Average railroad cut-offs to all CBDs in the MA & 22.488 & 8 \\
\hline Average expressway cut-offs to all CBDs in the MA & 13.982 & 0 \\
\hline Average impassable road cut-offs to all CBDs in the MA & 12.587 & 2 \\
\hline \multicolumn{3}{|l|}{ Panel B: Severance at the border } \\
\hline & Les 4000 & Chantereigne \\
\hline Road severance at the border (busy roads) & 0.609 & 0.554 \\
\hline Road severance at the border (big roads) & 0.508 & 0.146 \\
\hline Road severance at the border (expressways) & 0.438 & 0.111 \\
\hline Road severance at the border (highways) & 0.213 & 0 \\
\hline Road severance at the border (impassable roads) & 0.370 & 0.120 \\
\hline Road severance at the border (railroads) & 0.269 & 0.308 \\
\hline \multicolumn{3}{|c|}{ Panel C: Distance to transportation } \\
\hline & Les 4000 & Chantereigne \\
\hline Distance to closest rail or metro station & 0 & 1.740 \\
\hline Distance to closest highway junction & 11.012 & 0.045 \\
\hline Distance to closest airport & 3.409 & 1.912 \\
\hline \multicolumn{3}{|l|}{ Panel D: Catchment area } \\
\hline & Les 4000 & Chantereigne \\
\hline Share of ZFU less than 500m away from station & 0.651 & 0 \\
\hline Number of stations less than $500 \mathrm{~m}$ away from ZFU & 4 & 0 \\
\hline \multicolumn{3}{|l|}{ Panel E: Market potentials } \\
\hline & Les 4000 & Chantereigne \\
\hline Population access in the MA & 0.085 & 0.242 \\
\hline Road access in the MA & 0.044 & 0.106 \\
\hline Road access (weighted by traffic) in the MA & 0.046 & 0.103 \\
\hline Passenger station access in the MA & 0.089 & 0.284 \\
\hline
\end{tabular}

Note: (i) The cut-off variables give the number of cut-offs between the ZFU and each CBD of the MA weighted by the share of the corresponding CBD in the total population of CBD in the MA, divided by the number of CBD; (ii) Road severance is the proportion of the border of the ZFU that is within 100m of a transportation artery; (iii) Population, road and train station accesses are market potentials where variable $x$ in equation 1 in Briant, Lafourcade, and Schmutz (forth.) is respectively population, length of roads and number of train and metro stations; (iv) Distances are in $\mathrm{km}$.

Source: GIS SG-CIV and BD-TOPO. 
Figure 1: Two polar cases of ZFU: "Les 4000" and “Chantereigne-Montvilliers"
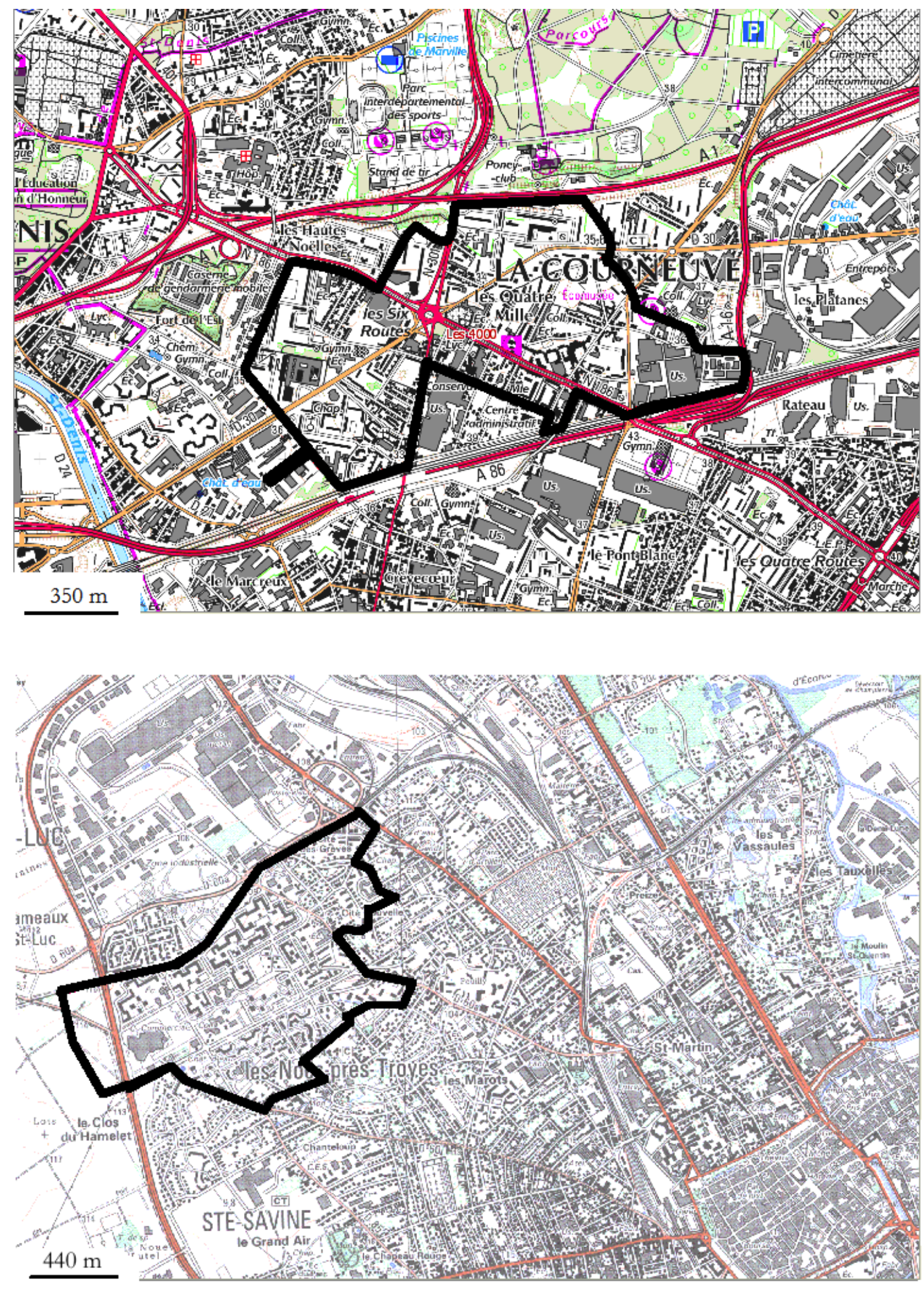

Note: (i) top: map of "Les 4000" (ZFU \#1119NZF) in the Parisian suburb of "La Courneuve"; bottom: map of "ChantereigneMontvilliers" (\#2118NZF) in the city of Troyes; (ii) The thick black lines are the borders of both ZFU, the purple lines in "Les 4000" are highways, whereas the orange lines in "Chantereigne-Montvilliers" are busy roads.

Source: GIS SG-CIV 
As shown on Figure 1, "Les 4000" is much more isolated from the rest of its MA than "Chantereigne" because of the numerous cut-offs that can be observed all around the border of the neighborhood. While $21.3 \%$ of the border of "Les 4000 " follow a highway, which is the maximum value among the whole population of ZFU, the corresponding value is zero for "Chantereigne". It is also less central: while the population-based and the station-based market potentials of "Chantereigne" correspond to the maximum values among the whole population of ZFU, these indicators are just equal to the average value among all ZFU for "Les 4000". On the other hand, "Les 4000" has better access to public transportation networks than "Chantereigne", which belongs to a small MA with little public infrastructure.

The respective values of these four indices for the ZFU “Les 4000" are 296 for severance, 281 for accessibility, 118 for centrality and 188 for the global index: this confirms that this ZFU is severely isolated from its immediate surroundings but quite well-connected to the public transportation network, and has a below-average position in terms of centrality within its metropolitan area. This all translates into a global isolation index slightly above average. As for our second polar example, the ZFU of "Chantereigne-Montvilliers" in Troyes has a severance index of 155, an accessibility index of 176, a centrality index of 268 , and a global index below the average, at 126: this confirms that this ZFU is rather spatially-integrated.

\subsection{Mobility in ZRU and ZFU2G}

Table 2 provides descriptive evidence that lack of mobility is clearly an issue in the case of ZRU/ZFU2G residents, using data drawn from the French National Household Travel Survey (hereafter, ENTD): unemployed residents in ZRU/ZFU2G spend, on average, 0.8 more days a week without setting foot outside their home, than their counterparts who live in other parts of the same city and have the same level of qualifications. One does not see how this gap might not impact their job-searching behavior. In this respect, the purpose of the EZ policy, namely to bring employment into these areas, is very relevant for spatially-isolated neighborhoods.

Going one step further, we can show that among the ZRU/ZFU2G unemployed residents, those located in a more spatially-isolated neighborhood are even less mobile. This is the purpose of Table 3, which displays the results from an OLS regression of the same mobility indicator as in Table 2, on each of our four indices of spatial isolation, employment status and the interaction of the two. Column (1) shows that a one standard-deviation increase in the global isolation index is associated with an additional half day at home for the unemployed. As shown in column (2), this result remains valid within the same metropolitan area. Columns (3) to (8) show that this correlation is also verified for the severance and the accessibility indices taken separately, but not for the centrality index. 
Table 2: Unemployed ZRU/ZFU2G residents spend more time at home

\begin{tabular}{lccc}
\hline Variables & $(1)$ & $(2)$ & $(3)$ \\
\hline ZRU/ZFU2G resident & 0.018 & -0.069 & -0.072 \\
& $(0.098)$ & $(0.100)$ & $(0.096)$ \\
Unemployed & $0.641^{* * *}$ & $0.568^{* * *}$ & $0.520^{* * *}$ \\
& $(0.127)$ & $(0.114)$ & $(0.112)$ \\
Unemployed ZRU/ZFU2G resident & $0.755^{*}$ & $0.794^{*}$ & $0.858^{* * *}$ \\
& $(0.438)$ & $(0.418)$ & $(0.318)$ \\
Diploma dummies & No & Yes & Yes \\
MA fixed effects & No & No & Yes \\
R-Squared & & & \\
\hline
\end{tabular}

Notes: (i) Ordinary-least-square estimates of the number of days spent without leaving home in the week before the survey; Standard deviations in parentheses are clustered by MA in columns (1) and (2); ${ }^{* * *} \mathrm{p}<0.01,{ }^{* *} \mathrm{p}<0.05,{ }^{*} \mathrm{p}<0.1$; (ii) Sample: random draw of one individual (part of the workforce) by household living in a metropolitan area which comprises a ZUS, excluding individuals living in ZFU1G; $\mathrm{N}=4880$; (iii) Regressions are weighted by sampling weights.

Source: ENTD 2007-2008.

Table 3: Spatial isolation increases the number of days spent at home by ZRU/ZFU2G residents

\begin{tabular}{lcccccccc}
\hline & \multicolumn{2}{c}{ Global index } & \multicolumn{2}{c}{ Severance index } & \multicolumn{2}{c}{ Accessibility index } & \multicolumn{2}{c}{ Centrality index } \\
& $(1)$ & $(2)$ & $(3)$ & $(4)$ & $(5)$ & $(6)$ & $(7)$ & $(8)$ \\
\hline Unemployed & $1.14^{* * *}$ & $1.26^{* * *}$ & $1.14^{* * *}$ & $1.18^{* * *}$ & $1.39^{* * *}$ & $1.77^{* * *}$ & $1.24^{* * *}$ & $1.53^{* * *}$ \\
& $(0.26)$ & $(0.29)$ & $(0.26)$ & $(0.34)$ & $(0.36)$ & $-(0.25)$ & $(0.37)$ & $(0.36)$ \\
Index & $0.13^{* *}$ & $0.26^{* *}$ & 0.03 & 0.23 & -0.12 & -0.11 & -0.08 & -0.28 \\
& $(0.054)$ & $(0.12)$ & $(0.09)$ & $(0.16)$ & $(0.10)$ & $(0.10)$ & $(0.06)$ & $(0.21)$ \\
Unemployed $\times$ Index & $0.47^{* * *}$ & $0.54^{* * *}$ & $0.65^{* * *}$ & $0.68^{* * *}$ & $-0.55^{* *}$ & $-0.74^{* * *}$ & -0.30 & -0.24 \\
& $(0.17)$ & $(0.20)$ & $(0.16)$ & $(0.23)$ & $(0.22)$ & $(0.21)$ & $(0.31)$ & $(0.27)$ \\
MA fixed effects & No & Yes & No & Yes & No & Yes & No & Yes \\
R-squared & 0.22 & 0.53 & 0.21 & 0.52 & 0.20 & 0.52 & 0.16 & 0.49 \\
\hline
\end{tabular}

Notes: (i) Ordinary-least-square estimates of the number of days spent without leaving home in the week before the survey; (ii) Standard deviations in parentheses: ${ }^{* * *} \mathrm{p}<0.01,{ }^{* *} \mathrm{p}<0.05,{ }^{*} \mathrm{p}<0.1$; in the specifications without MA fixed effects, standard errors are clustered at the MA level; (iii) All indices are standardized; (iv) Sample: random draw of one individual by household living in ZRU or ZFU2G, $\mathrm{N}=339$; (v) Regressions are weighted by sampling weights.

Source: ENTD 2007-2008, GIS SG-CIV and BD-TOPO. 


\section{Additional regression results}

\subsection{Annual treatment effects}

The evolution of the treatment effect is estimated with a similar specification as Equation 2 in Briant, Lafourcade, and Schmutz (forth.), except $\beta$ and the treatment variable $T_{i \tau t}=\mathbf{1}_{\tau \geq t_{0}} \times$ $\mathbf{1}_{i \in Z F U} \times \mathbf{1}_{\tau=t}$ are now time-varying:

$$
\Delta Y_{i \tau}=\alpha_{\tau}+\sum_{t} \beta_{t} T_{i \tau t}+\varepsilon_{i \tau}
$$

In that case, the coefficient $\beta_{t}$ identifies the incremental effect of the impact of the program in year $t$ and the coefficient $\beta_{t_{0}}$ identifies the immediate impact of the treatment on the evolution of the economic variable $Y$. As shown in Table 4 , the program was mostly effective in fostering firms' entry during its first year of implementation.

Table 4: Annual impact of the ZFU2G program

\begin{tabular}{lccccccc}
\hline & $\begin{array}{c}\text { Total inflows } \\
(1)\end{array}$ & $\begin{array}{c}\text { Creations } \\
(2)\end{array}$ & $\begin{array}{c}\text { Transfers } \\
(3)\end{array}$ & $\begin{array}{c}\text { Jobs } \\
(4)\end{array}$ & $\begin{array}{c}\text { Hours } \\
(5)\end{array}$ & $\begin{array}{c}\text { Average } \\
(6)\end{array}$ & $\begin{array}{c}\text { P90 } \\
(7)\end{array}$ \\
\hline Treatment first year & $0.168^{* *}$ & 0.059 & $0.453^{* * *}$ & 0.100 & 0.066 & -0.0019 & 0.008 \\
& $(0.078)$ & $(0.074)$ & $(0.085)$ & $(0.068)$ & $(0.061)$ & $(0.012)$ & $(0.018)$ \\
Treatment second year & 0.024 & 0.023 & 0.035 & $0.070^{*}$ & 0.033 & 0.011 & 0.025 \\
& $(0.047)$ & $(0.043)$ & $(0.089)$ & $(0.041)$ & $(0.039)$ & $(0.015)$ & $(0.018)$ \\
Treatment third year & 0.062 & 0.016 & 0.117 & NA & NA & NA & NA \\
& $(0.048)$ & $(0.045)$ & $(0.084)$ & NA & NA & NA & NA \\
Observations & & & & & & & \\
Number of MA & 3,301 & 3,256 & 1,379 & 2,714 & 2,714 & 2,714 & 2,714 \\
R-squared & 110 & 110 & 93 & 109 & 109 & 109 & 109 \\
& 0.014 & 0.006 & 0.028 & 0.023 & 0.021 & 0.004 & 0.004 \\
\hline
\end{tabular}

Notes: (i) In parentheses: standard errors clustered at the metropolitan area level; ${ }^{* * *} \mathrm{p}<0.01,{ }^{* *} \mathrm{p}<0.05,{ }^{*} \mathrm{p}<0.1$; (ii) Treatment stands for "average treatment"; The estimates correspond to the coefficients $\beta_{t}$ in equation 2 in Briant, Lafourcade, and Schmutz (forth.); (iii) The impact of the program on the stocks can only be observed with a one-year delay in comparison with flows. Since we restrict the focus to 2003-2006 for data consistency, the impact of the program on jobs, hours and wages can only be estimated for the first two years of treatment, and it is labeled as Not Applicable (NA) afterwards.

Source: SIRENE and DADS.

The impact of being targeted as ZFU2G on the growth rate of establishment inflows is an additional 17\% in 2004 (45\% for transfers). The effect of the program on the dynamics of firms' entry is no longer perceptible afterwards. However, given that the outcome studied here is the yearly growth rate of the flow of incoming establishments, this only means that the effect of the program on incoming establishments is roughly permanent. This one-shot increase in the growth regime of new settlements corroborates the linear impact found by Rathelot and Sillard (2008). Note, however, that we cannot assert with certainty that such a dynamic is also to be found in terms of job creation, given the low level of precision in the year-by-year estimates in column (4). 


\subsection{Robustness to the selection rule}

Table 5: Average impact of the program by share of IRIS in ZFU2G/ZRU

\begin{tabular}{|c|c|c|c|c|c|c|c|c|c|}
\hline \multicolumn{10}{|c|}{ Panel A: Total inflows } \\
\hline$\% I R I S \subset$ Zone & $>10 \%$ & $>20 \%$ & $>30 \%$ & $>40 \%$ & $>50 \%$ & $>60 \%$ & $>70 \%$ & $>80 \%$ & $>90 \%$ \\
\hline Treatment & $0.0774^{* *}$ & $0.0759^{* *}$ & $0.0921^{* *}$ & $0.0896^{* *}$ & $0.0846^{* *}$ & $0.0790^{* *}$ & $0.0859^{* *}$ & $0.0806^{* *}$ & $0.0748^{*}$ \\
\hline & $(0.0307)$ & $(0.0355)$ & $(0.0422)$ & $(0.0414)$ & $(0.0407)$ & $(0.0364)$ & $(0.0368)$ & $(0.0353)$ & $(0.0381)$ \\
\hline Observations & 5,303 & 4,628 & 4,071 & 3,644 & 3,301 & 3,020 & 2,618 & 2,305 & 1,998 \\
\hline \multicolumn{10}{|c|}{ Panel B: Creations } \\
\hline$\%$ IRIS $\subset$ Zone & $>10 \%$ & $>20 \%$ & $>30 \%$ & $>40 \%$ & $>50 \%$ & $>60 \%$ & $>70 \%$ & $>80 \%$ & $>90 \%$ \\
\hline Treatment & 0.0356 & 0.0343 & 0.0433 & 0.0404 & 0.0326 & 0.0289 & 0.0344 & 0.0260 & 0.0168 \\
\hline & $(0.0287)$ & $(0.0315)$ & $(0.0371)$ & $(0.0363)$ & $(0.0358)$ & $(0.0331)$ & $(0.0341)$ & $(0.0345)$ & $(0.0379)$ \\
\hline Observations & 5,223 & 4,557 & 4,015 & 3,596 & 3,256 & 2,976 & 2,578 & 2,269 & 1,965 \\
\hline \multicolumn{10}{|c|}{ Panel C: Transfers } \\
\hline$\% I R I S \subset$ Zone & $>10 \%$ & $>20 \%$ & $>30 \%$ & $>40 \%$ & $>50 \%$ & $>60 \%$ & $>70 \%$ & $>80 \%$ & $>90 \%$ \\
\hline Treatment & $0.114^{* * *}$ & $0.114^{* * *}$ & $0.151^{* * *}$ & $0.160^{* * *}$ & $0.184^{* * *}$ & $0.180^{* * *}$ & $0.187^{* * *}$ & $0.176^{* * *}$ & $0.173^{* * *}$ \\
\hline & $(0.0316)$ & $(0.0422)$ & $(0.0447)$ & $(0.0467)$ & $(0.0519)$ & $(0.0495)$ & $(0.0612)$ & $(0.0494)$ & $(0.0560)$ \\
\hline Observations & 2,559 & 2,146 & 1,806 & 1,562 & 1,379 & 1,242 & 1,044 & 902 & 774 \\
\hline \multicolumn{10}{|c|}{ Panel D: Jobs } \\
\hline \%IRIS $\subset$ Zone & $>10 \%$ & $>20 \%$ & $>30 \%$ & $>40 \%$ & $>50 \%$ & $>60 \%$ & $>70 \%$ & $>80 \%$ & $>90 \%$ \\
\hline Treatment & $0.0585^{* * *}$ & $0.0651^{* * *}$ & $0.0680^{* * *}$ & $0.0750^{* * *}$ & $0.0848^{* * *}$ & $0.0872^{* * *}$ & $0.0946^{* * *}$ & $0.0902^{* *}$ & $0.0992^{* * *}$ \\
\hline & $(0.0205)$ & $(0.0216)$ & $(0.0228)$ & $(0.0283)$ & $(0.0302)$ & $(0.0314)$ & $(0.0331)$ & $(0.0345)$ & $(0.0359)$ \\
\hline Observations & 4,348 & 3,804 & 3,348 & 2,992 & 2,714 & 2,482 & 2,150 & 1,899 & 1,640 \\
\hline \multicolumn{10}{|c|}{ Panel E: Hours } \\
\hline$\% I R I S \subset$ Zone & $>10 \%$ & $>20 \%$ & $>30 \%$ & $>40 \%$ & $>50 \%$ & $>60 \%$ & $>70 \%$ & $>80 \%$ & $>90 \%$ \\
\hline Treatment & 0.0337 & 0.0371 & 0.0405 & 0.0447 & 0.0498 & 0.0516 & 0.0589 & 0.0477 & 0.0612 \\
\hline & $(0.0207)$ & $(0.0232)$ & $(0.0250)$ & $(0.0317)$ & $(0.0343)$ & $(0.0354)$ & $(0.0394)$ & $(0.0394)$ & $(0.0410)$ \\
\hline Observations & 4,348 & 3,804 & 3,348 & 2,992 & 2,714 & 2,482 & 2,150 & 1,899 & 1,640 \\
\hline \multicolumn{10}{|c|}{ Panel F: Wages - Average } \\
\hline$\% I R I S \subset$ Zone & $>10 \%$ & $>20 \%$ & $>30 \%$ & $>40 \%$ & $>50 \%$ & $>60 \%$ & $>70 \%$ & $>80 \%$ & $>90 \%$ \\
\hline Treatment & 0.0043 & 0.0042 & 0.0040 & 0.0038 & 0.0044 & 0.0058 & 0.0110 & 0.0121 & 0.0111 \\
\hline & $(0.0043)$ & $(0.0047)$ & $(0.0056)$ & $(0.0059)$ & $(0.0055)$ & $(0.0060)$ & $(0.0068)$ & $(0.0078)$ & $(0.0084)$ \\
\hline Observations & 4,348 & 3,804 & 3,348 & 2,992 & 2,714 & 2,482 & 2,150 & 1,899 & 1,640 \\
\hline \multicolumn{10}{|c|}{ Panel G: Wages - P90 } \\
\hline$\% I R I S \subset$ Zone & $>10 \%$ & $>20 \%$ & $>30 \%$ & $>40 \%$ & $>50 \%$ & $>60 \%$ & $>70 \%$ & $>80 \%$ & $>90 \%$ \\
\hline Treatment & $0.0130^{* *}$ & $0.0132^{*}$ & $0.0141^{* *}$ & $0.0152^{* *}$ & $0.0167^{* *}$ & $0.0152^{* *}$ & $0.0227^{* *}$ & $0.0226^{* *}$ & 0.0170 \\
\hline & $(0.00622)$ & $(0.00679)$ & $(0.00678)$ & $(0.00754)$ & $(0.00741)$ & $(0.00729)$ & $(0.00912)$ & $(0.00974)$ & $(0.0104)$ \\
\hline Observations & 4,348 & 3,804 & 3,348 & 2,992 & 2,714 & 2,482 & 2,150 & 1,899 & 1,640 \\
\hline
\end{tabular}

Notes: (i) In parentheses: standard errors clustered at the metropolitan area level; ${ }^{* * *} \mathrm{p}<0.01,{ }^{* *} \mathrm{p}<0.05,{ }^{*} \mathrm{p}<0.1$; (ii) Treatment stands for "average treatment"; The estimates correspond to the coefficient $\beta$ in equation 2; (iii) \%IRIS $\subset Z$ one if the share of the IRIS intersecting a ZRU (respectively, ZFU2G) for the IRIS to be included in the control (respectively, treatment) group.

Source: SIRENE and DADS.

\section{References}

BRiant, A., M. LAfOURCADE, AND B. Schmutz (forth.): “Can tax breaks beat geography? Lessons from the French enterprise zone program," American Economic Journal: Economic Policy.

RAthelot, R., AND P. Sillard (2008): “Zones Franches Urbaines : quels effets sur l'emploi salarié et les créations d'établissements ?," Economie et Statistique, 415-416, 81-96. 